Article

\title{
The Cytosolic Oligosaccharide-Degrading Proteome of Butyrivibrio Proteoclasticus
}

\author{
Jonathan C. Dunne 1,2,3, William J. Kelly ${ }^{1}$, Sinead C. Leahy ${ }^{1}$, Dong Li ${ }^{1}$, Judy J. Bond ${ }^{1,2,3}$, \\ Lifeng Peng ${ }^{2}$, Graeme T. Attwood ${ }^{1}$ and T. William Jordan ${ }^{2, *}$
}

1 Rumen Microbiology, Animal Science Group, AgResearch Limited, Grasslands Research Centre, Palmerston North 4442, New Zealand; E-Mails: jonathan.dunne@gmri.org.nz (J.C.D.);

bill.kelly@agresearch.co.nz (W.J.K.); sinead.leahy@agresearch.co.nz (S.C.L.); dong.li@agresearch.co.nz (D.L.); jude.bond@dpi.nsw.gov.au (J.J.B.); graeme.attwood@agresearch.co.nz (G.T.A.)

2 Centre for Biodiscovery and School of Biological Sciences, Victoria University of Wellington, Wellington 6140, New Zealand; E-Mail: lifeng.peng@vuw.ac.nz

3 AgResearch Limited/Victoria University of Wellington Proteomics Laboratory, Victoria University of Wellington, Wellington 6140, New Zealand

* Author to whom correspondence should be addressed; E-Mail: bill.jordan@vuw.ac.nz; Tel.: +64-6-463-6092; Fax: +64-6-463-5331.

Academic Editors: Michael Hecker and Katharina Riedel

Received: 31 August 2015 / Accepted: 19 October 2015 / Published: 27 October 2015

\begin{abstract}
The growth and productivity of ruminants depends on a complex microbial community found in their fore-stomach (rumen), which is able to breakdown plant polysaccharides and ferment the released sugars. Butyrivibrio proteoclasticus $\mathrm{B} 316^{\mathrm{T}}$ is a Gram-positive polysaccharide-degrading, butyrate-producing bacterium that is present at high numbers in the rumen of animals consuming pasture or grass silage based diets. $\mathrm{B} 316^{\mathrm{T}}$ is one of a small number of rumen fibrolytic microbes capable of efficiently degrading and utilizing xylan, as well as being capable of utilizing arabinose, xylose, pectin and starch. We have therefore carried out a proteomic analysis of $\mathrm{B} 316^{\mathrm{T}}$ to identify intracellular enzymes that are implicated in the metabolism of internalized xylan. Three hundred and ninety four proteins were identified including enzymes that have potential to metabolize assimilated products of extracellular xylan digestion. Identified enzymes included arabinosidases, esterases, an endoxylanase, and $\beta$-xylosidase. The presence of intracellular debranching enzymes indicated that some hemicellulosic side-chains may not
\end{abstract}


be removed until oligosaccharides liberated by extracellular digestion have been assimilated by the cells. The results support a model of extracellular digestion of hemicellulose to oligosaccharides that are then transported to the cytoplasm for further digestion by intracellular enzymes.

Keywords: butyrivibrio proteoclasticus; carbohydrate active enzymes; hemicellulose; oligosaccharidases; proteomics; rumen; xylan

\section{Introduction}

The diet of pasture fed ruminants is rich in complex structural carbohydrates which rumen microbiota are able to digest to simpler sugar structures and provide energy for the host animal. In the cell walls of monocotyledonous grasses, xylan is the second most abundant structural carbohydrate behind cellulose and consists of a $\beta$-1,4-linked xylose backbone that may be substituted with $\alpha$-L-arabinofuranosyl, $O$-acetyl, and $\alpha$-glucuronic or 4 - $O$-methyl-D-glucuronic acid groups. The $\alpha$-L-arabinofuranosyl side groups may also be esterified with ferulic and p-coumaric acids that can form covalent linkages with other xylans or with lignin [1]. The chemically heterogeneous nature of xylan necessitates the synergistic activity of a variety of extracellular polysaccharide-degrading enzymes produced by rumen microbes. Using proteomic approaches the molecular machinery required to completely dissemble these insoluble, resilient and often underutilized food sources is being revealed. These enzymes include glycoside hydrolases (GHs) and carbohydrate esterases (CEs), that with others are classified in the Carbohydrate Active Enzymes database (CAZy, http://www.cazy.org) [2].

Butyrivibrio proteoclasticus $\mathrm{B} 316^{\mathrm{T}}[3,4]$ is a polysaccharide-degrading and butyrate-producing, Gram-positive microbe that is prevalent in the rumen of pasture grazing animals or those maintained on silage based diets [4-8]. B. proteoclasticus is one of only a small number of fibrolytic rumen microbes that are able to efficiently degrade and metabolize xylan, in addition to being able to utilize arabinose, xylose, pectin and starch [3,4]. The B. proteoclasticus genome encodes $114 \mathrm{GHs}$ that include endo-1,4- $\beta$-xylanases, $\beta$-xylosidases and $\alpha$-L-arabinofuranosidases [9], therefore providing the ability to grow well on xylan in vitro [3]. Kelly et al. [9] proposed a mechanism of extracellular polysaccharide breakdown whereby a group of nine cell-associated proteins that target xylan, pectin, and starch form the core of the extracellular catalytic potential. Recent examination by twodimensional electrophoresis (2DE) of the extracellular polysaccharide-degrading proteome of $B$. proteoclasticus supported this mechanism [10], and demonstrated that at least four (Xyn10B, Xsa43J, Pme8B, and Pel1A) of the nine extracellular enzymes are secreted when cells are grown using xylan as the only hemicellulosic carbon source. The endo-1,4- $\beta$-xylanase Xyn10B was significantly more abundant in the culture medium of xylan-grown cells, which suggests it plays a primary role in $B$. proteoclasticus mediated hemicellulose degradation. GH family 10 endoxylanases including Xyn10B are important for xylan breakdown due to their catalytic versatility, wide substrate specificity, and ability to hydrolyze heavily substituted xylooligosaccharides [11]. The homology of the Xyn10B catalytic and carbohydrate-binding domains to those in other enzymes indicates that Xyn10B is capable of liberating variable length xylooligomers from hemicellulose [12]. Additionally, the secreted 
xylosidase/arabinofuranosidase $\mathrm{Xsa} 43 \mathrm{~J}$ is expected to hydrolyze xylobiose, arabinoxylans and arabinogalactans. Several ATP-binding cassette (ABC) transporter substrate-binding proteins were also found to be significantly more abundant in the xylan-grown cell culture medium [10], and in the membrane proteome [13], which implies they are important for uptake of oligosaccharides derived from xylan disassembly.

Based on these results the proposed model of hemicellulose degradation and assimilation by B. proteoclasticus suggests extracellular hydrolysis of the xylan backbone of hemicellulose followed by transport of substituted or un-substituted xylooligosaccharides into the cell for further metabolism [10]. This model necessitates that $B$. proteoclasticus possesses the intracellular catalytic machinery that allows cells to rapidly degrade and metabolize the internalized oligosaccharides. The $B$. proteoclasticus genome encodes 90 predicted cytosolic oligosaccharide-degrading enzymes that collectively represent 38 distinct GH, CE, and glycosyl transferase (GT) families [9]. Members of the $\mathrm{GH} 2$, GH3, GH13, GH31, and GH43 families are the most prevalent. Notably, all of the GH2 and GH31 enzymes and most of the GH3, GH13, and GH43 enzymes are predicted to be localized to the cytosol.

We have therefore now carried out a proteomic analysis of cytosolic fractions from B. proteoclasticus grown on xylan or xylose with the goal of identification of intracellular carbohydrate active enzymes associated with the further metabolism of the products of extracellular digestion of polysaccharides. Two previously described proteomic workflows [10,13] were used: (1) separation of proteins by 2DE followed by use of matrix-assisted laser desorption ionization time-offlight (MALDI-TOF and TOF/TOF) mass spectrometry for identification of protein spots excised from the gels; and (2) liquid chromatography-tandem mass spectrometry (LC-MS/MS) of tryptic digests of the cytosolic samples.

\section{Experimental Section}

\subsection{Sample Preparation}

B. proteoclasticus cells were grown at $37{ }^{\circ} \mathrm{C}$ under anaerobic conditions in modified DSM Medium 704 that included $0.2 \%$ yeast extract and $0.2 \%$ trypticase peptone, with either $0.1 \%(w / v)$ oat-spelt xylan or $0.5 \%(w / v)$ xylose $[10,13]$. Mid-log phase and stationary phase cultures were harvested at approximately $\mathrm{OD}_{600} 0.5$ and $\mathrm{OD}_{600} 0.7$, respectively. Cells were separated from the culture medium by centrifugation at $3000 \times \mathrm{g}$ for $30 \mathrm{~min}$ at $4{ }^{\circ} \mathrm{C}$. The cell pellet was then resuspended in $10 \mathrm{~mL}$ of ice-cold $50 \mathrm{mM}$ Tris- $\mathrm{HCl}(\mathrm{pH} 7.0)$ lysis buffer containing $2 \%(w / v)$ CHAPS, cOmplete ${ }^{\circledR}$ Protease Inhibitor (Roche Applied Science, Mannheim, Germany), and $100 \mathrm{mg}$ of Zirconia/Silica Beads (Biospec Products, Bartlesville, OK, USA) and the cells were lysed by bead-beating for 5 min using a FastPrep FP120-230 bead beater (MP Biomedicals, Santa Ana, CA, USA). The disrupted cell suspension was centrifuged at $16,000 \times \mathrm{g}$ for $30 \mathrm{~min}$ at $4{ }^{\circ} \mathrm{C}$ to pellet the beads and cell debris. The supernatant containing the soluble cytosolic fraction was removed and stored immediately at $-80{ }^{\circ} \mathrm{C}$.

Protein extracts were purified using the phenol/methanol/ammonium acetate procedure described by Carpentier et al. [14]. Briefly, the cell supernatant was mixed with an equal volume of ice-cold Tris- $\mathrm{HCl}$ buffered phenol $(\mathrm{pH} 8.0)$ and vortexed vigorously for $30 \mathrm{~min}$ at $4{ }^{\circ} \mathrm{C}$. The mixture was centrifuged at $8000 \times \mathrm{g}$ for $5 \mathrm{~min}$ and the phenolic phase was removed and placed in a fresh $1.5 \mathrm{~mL}$ 
microcentrifuge tube with an equal volume of ice-cold $50 \mathrm{mM}$ Tris- $\mathrm{HCl}(\mathrm{pH} \mathrm{7.0)}$. The mixture was vigorously vortexed for $30 \mathrm{~min}$ at $4{ }^{\circ} \mathrm{C}$ and then centrifuged at $8000 \times g$ for $5 \mathrm{~min}$ and the phenol phase removed and placed in a fresh $1.5 \mathrm{~mL}$ microcentrifuge tube. Proteins were precipitated by the addition of 4 vols of $-20{ }^{\circ} \mathrm{C}$ methanol containing $100 \mathrm{mM}$ ammonium acetate. The mixture was vigorously vortexed for $60 \mathrm{~s}$ and incubated overnight at $-20{ }^{\circ} \mathrm{C}$. The precipitated protein was pelleted by centrifugation at $13,600 \times \mathrm{g}$ for $60 \mathrm{~min}$ at $4{ }^{\circ} \mathrm{C}$, and the protein pellet was air-dried in a fume cupboard overnight.

\subsection{Two-Dimensional Electrophoresis and Image Analysis}

Protein samples were resuspended in $7 \mathrm{M}$ urea, $2 \mathrm{M}$ thiourea, 2\% (w/v) CHAPS and $50 \mathrm{mM}$ dithiothreitol and incubated overnight at $4{ }^{\circ} \mathrm{C}$ with shaking. Protein concentration was assayed using a 2-D Quant Kit (GE Healthcare, Uppsala, Sweden). Each sample was supplemented with 0.5\% (v/v) Immobilized pH Gradient (IPG) Buffer (GE Healthcare, Uppsala, Sweden) and $125 \mu \mathrm{L}$ was applied to $7 \mathrm{~cm}$ IPG strips that were passively rehydrated at room temperature for $16 \mathrm{~h}$. Isoelectricfocusing (IEF), followed by second-dimension SDS-PAGE, and staining with colloidal Coomassie Brilliant Blue G250 was as previously described [10]. Briefly, IEF was for 9-11 kVh in an IPGphor (GE Healthcare, Uppsala, Sweden) followed by incubation of focused IPG strips for $15 \mathrm{~min}$ in $1 \times$ LDS Buffer (Invitrogen, Carlsbad, CA, USA) with $1 \times$ Reducing Agent (Invitrogen, Carlsbad, CA, USA), then for $15 \mathrm{~min}$ in LDS Sample Buffer containing $100 \mathrm{mM}$ iodoacetamide. Second dimension electrophoresis was at $200 \mathrm{~V}$ using NuPAGE ${ }^{\circledR}$ Novex $4 \%-12 \%$ Bis-Tris ZOOM $^{\circledR}$ gels in a NuPAGE ${ }^{\circledR}$ MOPS Buffer (Invitrogen, Carlsbad, CA, USA). Three biological replicates were analyzed for each growth condition, and each biological replicate was analyzed in triplicate (nine gels per treatment). Stained gels were scanned using a Molecular Dynamics Personal Densitometer SI (Sunnyvale, CA, USA). Image Master $^{\text {TM }}$ 2D Platinum software (Version 5.0, GE Healthcare, Uppsala, Sweden) was used for gel analysis. Protein spot volumes were calculated for each spot that could be matched in at least seven of the nine analyzed replicate gels for each treatment. All detected spots were given C (cytosol fraction) numbers. A larger number of spots was detected from mid-log growth phase cells (1264 spots) compared to stationary phase cells (1180 spots). All spot volumes were within the linear range previously defined for colloidal Coomassie staining [10]. Missing data points were imputed using the lowest spot volume value for that protein detected on other gels. SPSS (Statistical Package for the Social Sciences) (Version 14.0, IBM Corporation, New York, NY, USA) software was used for statistical analysis with two-tailed Student $t$-tests $(p<0.01)$ to assess statistical significance of protein abundance changes.

\subsection{Identification of Proteins Excised from $2 D E$ Gels}

Protein spots excised from stained 2DE gels were prepared for peptide mass fingerprinting using an Ettan Digester (GE Healthcare, Uppsala, Sweden) with $25 \mathrm{ng}$ trypsin per gel plug [15]. Extracted tryptic peptides were resuspended in $1.5 \mu \mathrm{L}$ of $10 \mathrm{mg} \cdot \mathrm{mL}^{-1} \alpha$-cyano-4-hydroxycinnamic acid in $50 \%$ acetonitrile: $0.1 \%$ trifluoroacetic acid $(v / v)$ and analyzed using a Voyager DE Pro MALDI-TOF mass spectrometer (Applied Biosystems, Foster City, CA, USA) as previously described [10,13,16]. MALDI MS/MS using an ABSCIEX 5800 TOF/TOF mass spectrometer (SCIEX, Framingham, MA, USA) was 
used for repeat analysis of protein spots that contained fibrolytic enzymes. TOF/TOF analysis parameters were: parent ion spectra by accumulating four sub-spectra each of 200 laser shots and spectra; then the 15 most intense ions per MS spectrum ( $\mathrm{S} / \mathrm{N}>10)$ were selected for MS/MS analysis and fragment ion spectra were acquired by accumulating four sub-spectra each of 250 laser shots using air as the collision gas.

\section{4. $L C-M S / M S$}

Precipitated cytosolic protein extracts were resuspended in $8 \mathrm{M}$ urea, $100 \mathrm{mM}$ Tris- $\mathrm{HCl}(\mathrm{pH} 8.5)$ at a final concentration of $0.4 \mu \mathrm{g} \cdot \mu \mathrm{L}^{-1}$. Protein disulfide bonds were reduced with $10 \mathrm{mM}$ dithiothreitol at $56{ }^{\circ} \mathrm{C}$ for $30 \mathrm{~min}$, followed by alkylation with $55 \mathrm{mM}$ iodoacetamide at room temperature for $40 \mathrm{~min}$ in the dark in the urea-buffer solution. The reduced and alkylated samples were diluted four-fold with $100 \mathrm{mM}$ Tris-HCl ( $\mathrm{pH} \mathrm{8.5)}$ and digested with trypsin (Roche, modified sequencing grade) at an enzyme-to-substrate ratio of $1: 50 \mathrm{w} / \mathrm{w}$ with $1 \mathrm{mM} \mathrm{CaCl}_{2}$ overnight at $37^{\circ} \mathrm{C}$. Digestion was stopped by addition of formic acid to $4 \%(v / v)$ final concentration. LC-MS/MS was carried out as previously described [16] using a Finnigan LTQ ${ }^{\mathrm{TM}}$ Linear Ion-trap (Thermo Scientific, Waltham, MA, USA) with a Dionex UltiMate ${ }^{\circledR} 3000$ Nano HPLC system (Thermo Scientific, Waltham, MA, USA) containing an Acclaim ${ }^{\circledR}$ PepMapTM C18 nano-column $(75 \mu \mathrm{m}$ i.d. $\times 15 \mathrm{~cm}, 100 \AA$ pore size $)$. The mobile phase gradient was constructed from $0.1 \%$ formic acid $(v / v)$ (Solvent A) and $80 \%$ acetonitrile: $0.1 \%$ formic acid $(v / v)$ (Solvent B). The gradient consisted of 0 to $15 \%$ linear gradient Solvent B over 25 min; $15 \%$ to $35 \%$ linear gradient Solvent B from 25 to $67 \mathrm{~min} ; 35 \%$ to $100 \%$ linear gradient Buffer B from 67 to 77 min. Each biological replicate was analyzed five times to give 15 replicate raw data files per growth substrate. LC-MS/MS data files were processed using BioWorks 3.3.1 (Thermo Scientific, Waltham, MA, USA).

\subsection{Bioinformatics}

MALDI-TOF peak mass lists and MS/MS data files were searched in-house using MASCOT (Version 2.2.03) [17] against the functionally annotated B. proteoclasticus genome sequence database (Genbank Accession Numbers CP001810-CP001813). MASCOT search parameters were: one missed tryptic cleavage site; cysteine carbamidomethylation and methionine oxidation as fixed and variable modifications respectively; $50 \mathrm{ppm}$ and $0.5 \mathrm{Da}$ maximum mass tolerance for parent and fragment ions. The peptide false discovery rate (FDR) was determined by calculating the ratio of the number of unique peptides matched to the reverse protein sequences over the number of peptides matched to the reverse and forward protein sequences.

For analysis of LC-MS/MS spectra BioWorks search parameters were optimized to obtain a peptide FDR of less than $1 \%$. Following peptide to protein assignment, the protein expectation value (less than $1.0 \times 10^{-4}$ ), peptide cross correlation scores (greater than 1.5 for single charge, 2.5 for double charge and 3.3 for triple charge), and minimum number of matched peptides per protein (minimum 2) were used as filters to obtain an average protein FDR across all technical replicate search results of below $1 \%$. Protein FDR was calculated as the ratio of the number of proteins matched to the reverse protein sequences over the number of proteins matched to the reverse and forward protein sequences, 
respectively. Proteins were included in the BioWorks identification dataset only if they were identified with statistical significance in at least two of the three biological replicate samples.

Protein isoelectric point and size were calculated as previously described [10]. Also as before, Pfam, Tigrfam, BLASTp and ClustalW [18-21] were used to predict protein functional domains and sequence alignments. Signal peptides were predicted using SignalP 3.0 [22], LipoP 1.0 [23] and pattern searching as recommended for Gram-positive bacteria [24]. TMHMM 2.0 [25] and SOSUI/G [26] were used to predict membrane spanning domains.

\section{Results and Discussion}

\subsection{Theoretical Proteome}

The theoretical 2DE map of the B. proteoclasticus intracellular cytoplasmic proteome (Figure 1) was dominated by acidic proteins: $79 \%$ (2242) of the predicted cytoplasmic proteins possessed a theoretical $\mathrm{p} I<7$, and 89 of the 90 predicted cytoplasmic oligosaccharide-degrading enzymes had a $\mathrm{p} I<6.8$ with a cluster of 81 enzymes between $\mathrm{p} I 4$ and 5.6. Ninety percent of the predicted cytoplasmic proteome (2575 proteins) had predicted polypeptide masses between 10 and $150 \mathrm{kDa}$, and all cytoplasmic oligosaccharidases had a predicted size between 26 and $134 \mathrm{kDa}$. The group of 802 proteins with a predicted $\mathrm{p} I$ value $>6.5$ was dominated by hypothetical proteins and mobile elements (transposases), as well as proteins involved in nucleic acid metabolism, protein synthesis, transcriptional regulation, and cell envelope biogenesis. Following initial 2DE using pH 3-10 IEF strips, all further analysis was carried out using narrow range focusing to enhance separation of the acidic proteins.

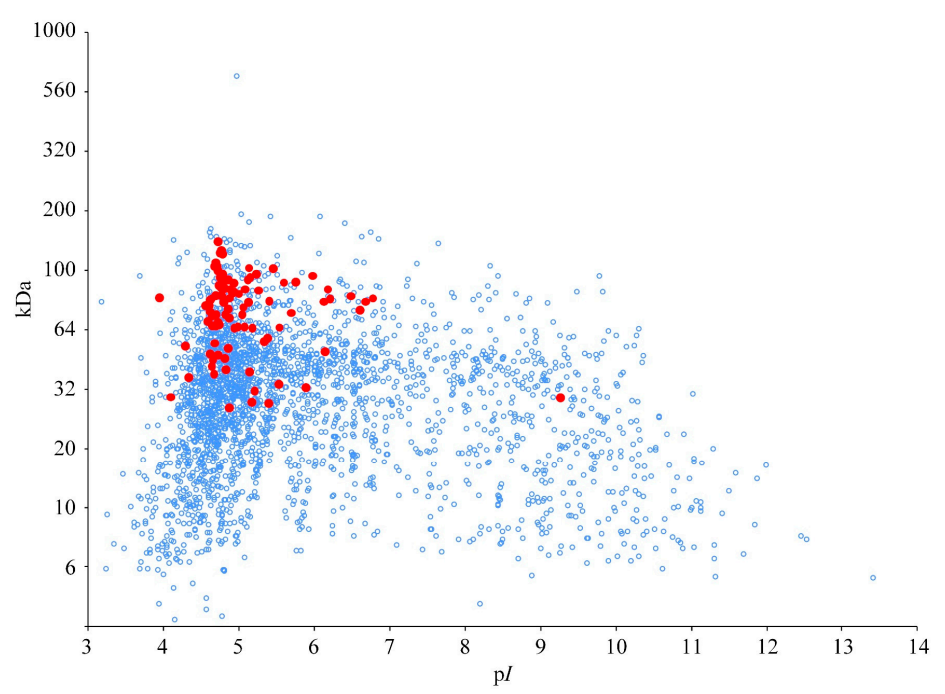

Figure 1. Theoretical 2DE map of the B. proteoclasticus cytoplasmic proteins. Red spots represent predicted oligosaccharide-degrading enzymes. Blue open circles represent all other cytoplasmic proteins. The y-axis is presented in logarithmic scale to represent separation of proteins by $2 \mathrm{DE}$. 


\subsection{Identification of Proteins Separated by $2 D E$}

Cytosolic subcellular fractions from cells harvested at mid-log or stationary growth phase were analyzed using 2DE of multiple gels ( $\mathrm{p} I$ 3-5.6, 5.3-6.5, 6-11 IEF), followed by MALDI-TOF and MALDI-TOF/TOF analysis of tryptic digests of protein spots excised from the gels. Proteins were identified from 481 of 625 excised spots, and were the products of 219 genes. Table 1 summarizes the 17 2DE spots (Figure 2) from which 15 different enzymes that are predicted to be associated with catabolism of oligosaccharides were identified. All enzymes were identified from the $\mathrm{p} I 3-5.62 \mathrm{DE}$ separations. Two protein spots, $\mathrm{C} 1120$ and $\mathrm{C} 1147$, contained more than one glycosidase. C1147 contained $\beta$-galactosidase $\mathrm{Bga} 2 \mathrm{~B}, \beta$-glucosidase $\mathrm{Bg} 13 \mathrm{C}$ and $\beta$-mannosidase Man2A. The predicted $\mathrm{p} I$ and size of the three enzymes were similar. Spot C1120 contained $\beta$-galactosidase Bga35B and $\beta$-xylosidase Xyl3A, both of which were also of similar predicted $\mathrm{p} I$ and size. Other identified proteins are listed in Supplementary Table S1 including 28 enzymes from intracellular pathways of carbohydrate metabolism and 11 oligosaccharide ABC-transporter associated proteins.

Table 1. Summary of the oligosaccharidases identified by 2DE/MALDI-TOF/TOF in the B. proteoclasticus cytosol.

\begin{tabular}{|c|c|c|c|c|c|c|c|c|}
\hline Spot & Protein & Locus & $\begin{array}{l}\text { Protein } \\
\text { Pilot Score }\end{array}$ & Expect. $^{i}$ & SigP ii & $\mathbf{p} I$ & kDa & Pep iii \\
\hline C901 & $\beta$-Galactosidase, Bga2A & Bpr_I0279 & 239 & $4.8 \times 10^{-21}$ & $\mathrm{~N}$ & 4.7 & 118.7 & 31 \\
\hline C1147 & $\beta$-Galactosidase, Bga2B & Bpr_III209 & 80 & $4.1 \times 10^{-5}$ & $\mathrm{~N}$ & 4.8 & 91.1 & 19 \\
\hline C1147 & $\beta$-Mannosidase, Man2A & Bpr_III237 & 117 & $3.8 \times 10^{-8}$ & $\mathrm{~N}$ & 4.8 & 95.9 & 20 \\
\hline C1147 & $\beta$-Glucosidase, Bgl3C & Bpr_I0138 & 73 & $1.8 \times 10^{-4}$ & $\mathrm{~N}$ & 4.9 & 91.5 & 10 \\
\hline C1136 & $\beta$-Glucosidase, Bgl3B & Bpr_I0847 & 94 & $1.4 \times 10^{-6}$ & $\mathrm{~N}$ & 4.7 & 103.7 & 24 \\
\hline C671 & $\beta$-Glucosidase, Bgl3B & Bpr_I0847 & 218 & $6.1 \times 10^{-19}$ & $\mathrm{~N}$ & 4.7 & 91.5 & 23 \\
\hline C760 & $\beta$-Glucosidase, Bgl3C & Bpr_I0138 & 72 & $2.4 \times 10^{-4}$ & $\mathrm{~N}$ & 4.9 & 91.5 & 7 \\
\hline C761 & $\beta$-Glucosidase, Bgl3C & Bpr_I0138 & 231 & $3.0 \times 10^{-20}$ & $\mathrm{~N}$ & 4.9 & 103.7 & 23 \\
\hline C1120 & $\beta$-Xylosidase, Xyl3A & Bpr_I0184 & 397 & $7.6 \times 10^{-37}$ & $\mathrm{~N}$ & 4.8 & 78.2 & 28 \\
\hline C1120 & $\beta$-Galactosidase, Bga35B & Bpr_I2006 & 87 & $6.9 \times 10^{-6}$ & $\mathrm{~N}$ & 4.9 & 83.2 & 12 \\
\hline C637 & Pullulanase, Pul13A & Bpr_III161 & 191 & $3.0 \times 10^{-16}$ & $\mathrm{Y}$ & 4.4 & 99.7 & 19 \\
\hline C638 & Pullulanase, Pul13A & Bpr_III161 & 243 & $1.9 \times 10^{-21}$ & Y & 4.4 & 99.7 & 22 \\
\hline C644 & Glycoside hydrolase family $30, \mathrm{GH} 30 \mathrm{~A}$ & Bpr_I2937 & 261 & $3.0 \times 10^{-23}$ & Y & 4.3 & 67.0 & 23 \\
\hline C679 & Glycoside hydrolase family $31, \mathrm{GH} 31 \mathrm{C}$ & Bpr_I1974 & 301 & $3.0 \times 10^{-27}$ & $\mathrm{~N}$ & 4.7 & 78.2 & 40 \\
\hline C680 & Glycoside hydrolase family $31, \mathrm{GH} 31 \mathrm{C}$ & Bpr_I1974 & 248 & $6.1 \times 10^{-22}$ & $\mathrm{~N}$ & 4.7 & 78.2 & 39 \\
\hline $\mathrm{C} 1054$ & $\alpha$-Galactosidase, Aga36C & Bpr_III065 & 315 & $1.2 \times 10^{-28}$ & $\mathrm{~N}$ & 5.1 & 83.2 & 30 \\
\hline $\mathrm{C} 1075$ & $\begin{array}{l}\text { Xylosidase/arabino-furanosidase, } \\
\text { Xsa43A }\end{array}$ & Bpr_I0302 & 110 & $3.8 \times 10^{-8}$ & $\mathrm{Y}$ & 4.3 & 57.5 & 17 \\
\hline C1082 & $\alpha$-D-Glucuronidase, Agu67A & Bpr_I0177 & 341 & $3.0 \times 10^{-31}$ & $\mathrm{~N}$ & 4.9 & 76.1 & 32 \\
\hline $\mathrm{C} 1035$ & Feruloyl esterase, Est1E & Bpr_I2870 & 82 & $2.7 \times 10^{-5}$ & $\mathrm{~N}$ & 5.2 & 27.8 & 13 \\
\hline $\mathrm{C} 1017$ & Acetyl-xylan esterase, Est2A & Bpr_I2939 & 235 & $1.2 \times 10^{-20}$ & $\mathrm{~N}$ & 4.8 & 42.4 & 8 \\
\hline
\end{tabular}

${ }^{i}$ Expectation value is the statistical probability of the top ranked protein match being a false positive identification, $p<0.05$; ii Secretory signal-peptides were predicted using SignalP (Version 3.0, Technical University of Denmark, Lyngby, Denmark), LipoP (Version 1.0, University of Denmark, Lyngby, Denmark) and pattern searching as recommended for Gram-positive bacteria [22-24]; iii Number of tryptic peptides matched to the full length protein sequence. 


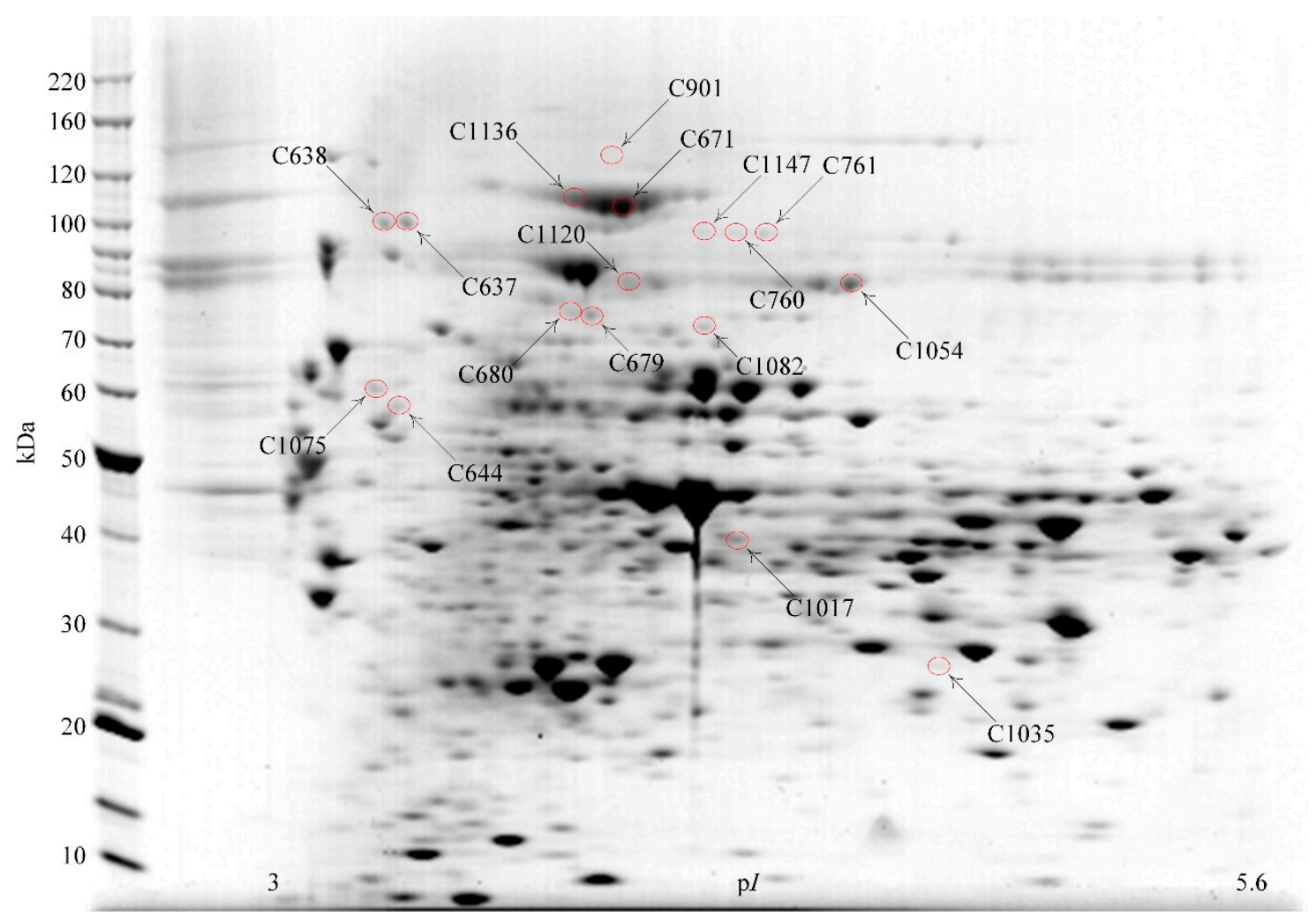

Figure 2. Oligosaccharide degrading enzymes identified in the $B$. proteoclasticus cytosol by 2DE/MALDI-TOF/TOF. A Coomassie-stained 2DE gel (p/ 3-5.6) is shown of cytosolic proteins harvested from mid-log phase cells that had been grown in xylan. Circled spots indicate the identified oligosaccharidases that are summarized in Table 1.

\subsection{Protein Identification by LC-MS/MS}

Tryptic digests of cytosolic extracts from xylan-grown and xylose-grown, mid-log phase cells were digested and analyzed by LC-MS/MS, using three separate cultures (biological replicates) for each condition and each biological replicate analyzed by LC MS/MS five times. A total of 329 non-redundant proteins were identified including 50 proteins involved in carbohydrate metabolism, 20 of which were oligosaccharidases (Table 2). Notably, nine of these had not been identified by the 2DE-based analyses, bringing the total number of oligosaccharidases identified in the cytosol of $B$. proteoclasticus cells to 24 (15 enzymes identified from 2D gels plus nine new identifications by LC-MS/MS). Similar to the pattern observed in the gel-based analyses, all LC-MS/MS identified enzymes had a predicted $\mathrm{p} I$ value within a narrow range between 4.1 and 6 . Other identified proteins are listed in Supplementary Table S2.

Figure 3 summarizes the functional analysis of all proteins identified either from the 2DE gels or by LC-MS/MS. Carbohydrate metabolism was the major class, comprising $16.2 \%$ of the total 394 protein identifications. In accordance with the predicted metabolic pathways of B. proteoclasticus [9], enzymes from the pentose phosphate pathway and enzymes involved in production of butyrate and formate were detected (Supplementary Tables S1 and S2). Other major classes included protein synthesis, transporters, amino acid biosynthesis and energy metabolism. 
Table 2. Summary of oligosaccharide degrading enzymes identified by LC-MS/MS i

\begin{tabular}{|c|c|c|c|c|c|c|}
\hline Protein & Locus & Expect. ii & SigP iii & $\mathrm{p} I$ & kDa & Pep iv \\
\hline$\beta$-Galactosidase, Bga2A & Bpr_I0279 & $1.5 \times 10^{-12}$ & $\mathrm{~N}$ & 4.7 & 118.7 & 8 \\
\hline$\beta$-Mannosidase, Man2A & Bpr_III237 & $3.1 \times 10^{-11}$ & $\mathrm{~N}$ & 4.8 & 95.9 & 7 \\
\hline$\beta$-Glucosidase, Bgl3A & Bpr_I0693 & $2.5 \times 10^{-6}$ & $\mathrm{Y}$ & 4.1 & 115.6 & 23 \\
\hline$\beta$-Glucosidase, Bgl3B & Bpr_I0847 & $2.6 \times 10^{-11}$ & $\mathrm{~N}$ & 4.7 & 103.7 & 7 \\
\hline$\beta$-Glucosidase, Bgl3C & Bpr_I0138 & $8.1 \times 10^{-7}$ & $\mathrm{~N}$ & 4.9 & 91.5 & 2 \\
\hline$\beta$-Xylosidase Xyl3A & Bpr_I0184 & $8.9 \times 10^{-15}$ & $\mathrm{~N}$ & 4.8 & 78.2 & 42 \\
\hline Cellodextrinase, Ce19B & Bpr_I1593 & $1.0 \times 10^{-30}$ & $\mathrm{~N}$ & 4.6 & 61.0 & 22 \\
\hline Endo-1,4- $\beta$-xylanase and esterase, Xyn10D & Bpr_I1083 & $3.6 \times 10^{-10}$ & $\mathrm{~N}$ & 5.0 & 79.7 & 5 \\
\hline$\alpha$-Amylase, Amy13G & Bpr_I0729 & $1.7 \times 10^{-11}$ & $\mathrm{~N}$ & 4.7 & 60.3 & 3 \\
\hline Pullulanase, Pul13A & Bpr_III161 & $1.1 \times 10^{-10}$ & $\mathrm{Y}$ & 4.4 & 99.7 & 7 \\
\hline Glycoside hydrolase family 31 , GH31C & Bpr_I1974 & $1.0 \times 10^{-11}$ & $\mathrm{~N}$ & 4.7 & 78.2 & 32 \\
\hline$\beta$-Galactosidase, Bga35B & Bpr_I2006 & $3.1 \times 10^{-10}$ & $\mathrm{~N}$ & 4.9 & 83.2 & 4 \\
\hline$\alpha$-Galactosidase, Aga36C & Bpr_III065 & $9.3 \times 10^{-5}$ & $\mathrm{~N}$ & 5.1 & 83.2 & 7 \\
\hline Xylosidase/arabinofuranosidase and esterase, $\mathrm{Xsa} 43 \mathrm{H}$ & Bpr_I0301 & $1.6 \times 10^{-8}$ & $\mathrm{~N}$ & 4.7 & 107.9 & 7 \\
\hline$\alpha$-L-Arabinofuranosidase, Arf51A & Bpr_I0329 & $1.1 \times 10^{-15}$ & $\mathrm{~N}$ & 5.2 & 57.0 & 14 \\
\hline$\alpha$-D-Glucuronidase, Agu67A & Bpr_I0177 & $4.9 \times 10^{-11}$ & $\mathrm{~N}$ & 4.9 & 76.1 & 22 \\
\hline$\alpha$-L-Rhamnosidase, Rha78A & Bpr_I1686 & 99.9 & $\mathrm{~N}$ & 4.8 & 85.0 & 3 \\
\hline Cellobiose phosphorylase, Cbp94A & Bpr_I2447 & $1.1 \times 10^{-16}$ & $\mathrm{~N}$ & 5.1 & 91.5 & 6 \\
\hline Feruloyl esterase, Est1E & Bpr_I2870 & $1.3 \times 10^{-10}$ & $\mathrm{~N}$ & 5.2 & 27.8 & 5 \\
\hline Glycogen phosphorylase, Glgp2 & Bpr_I2847 & $1.8 \times 10^{-10}$ & $\mathrm{~N}$ & 6.0 & 94.8 & 10 \\
\hline
\end{tabular}

${ }^{\mathrm{i}}$ Proteins shown in bold were uniquely identified by 1D LC-MS/MS; ii Expectation value is the statistical probability of the top ranked protein match being a false positive identification, $p<0.05$; iii Secretory signal-peptides were predicted using SignalP (Version 3.0), LipoP (Version 1.0) and pattern searching as recommended for Gram-positive bacteria [22-24]; iv Number of tryptic peptides matched to the full length protein sequence.

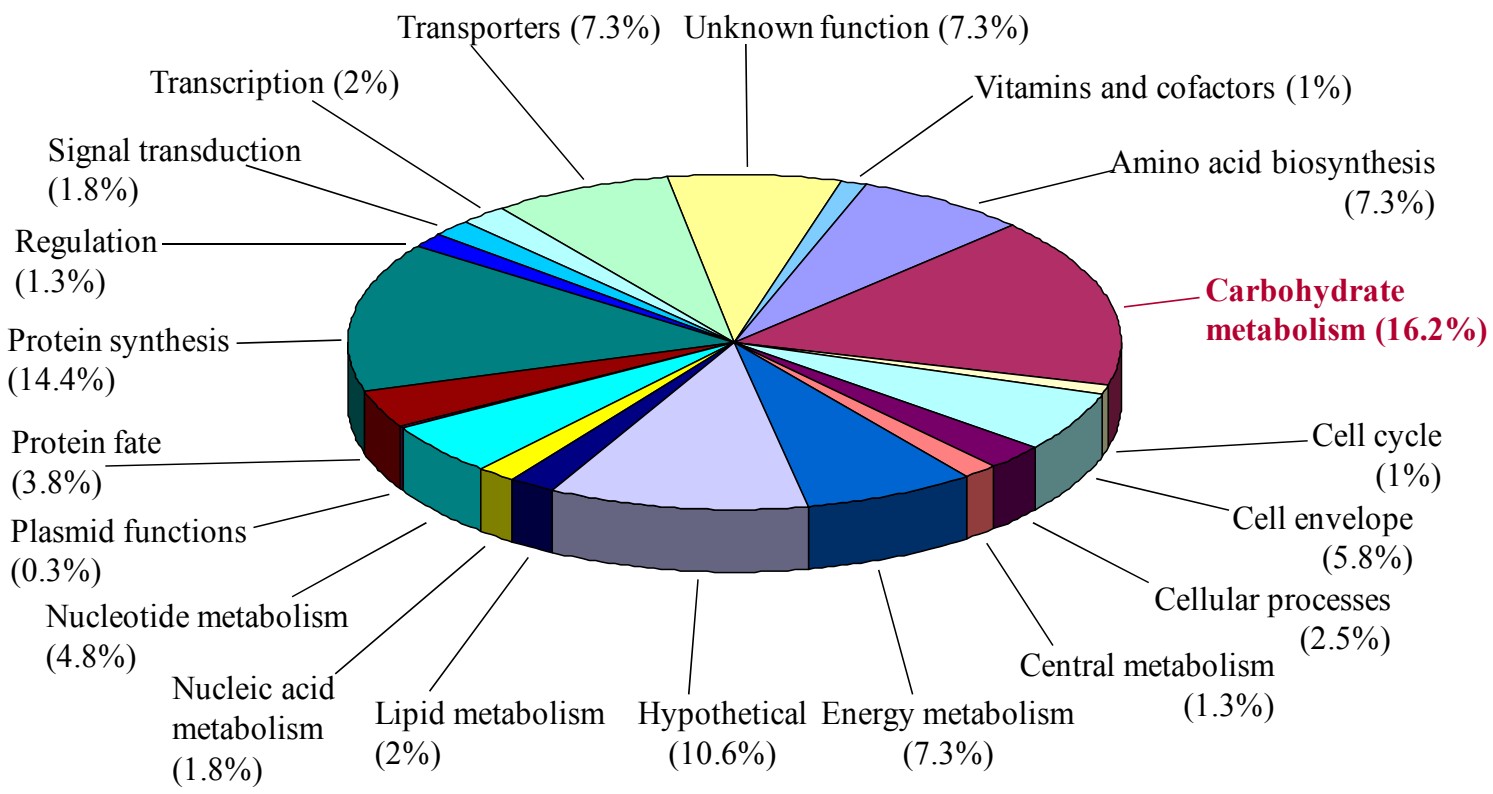

Figure 3. Protein function summary of all proteins identified in the B. proteoclasticus cytosol. 


\subsection{Functional Domains of the Oligosaccharidases}

Pfam, BLASTp and Tigrfam analyses were used to predict carbohydrate active domains in each oligosaccharidase amino acid sequence. Four proteins, $\beta$-glucosidase Bgl3A, glycoside hydrolase GH30A, pullulanase Pul13A, and xylosidase/arabinofuranosidase Xsa43A, were each predicted to contain an N-terminal secretory signal peptide (Figure 4). Bgl3A and Pul13A also contained a predicted transmembrane helix within the C-terminal region, while GH30A and Xsa43A contained lipobox motifs at the N-terminus. It is therefore possible that Bgl3A and Pul13A are membrane-anchored proteins and that GH30A and Xsa43A are cell wall lipoproteins. Although cross-contamination of the cytosolic subcellular fraction by proteins released from the membrane or cell wall is possible, it should be noted that none of the four proteins were detected in the previously reported membrane [13] or secreted [10] fractions. Like some of the extracellular polysaccharidases [10], the potentially membrane anchored GH13 pullulanase and secreted GH43 xylosidase/arabinofuranosidase Xsa43A contained carbohydrate-binding modules (CBMs). CBM48 modules mediate enzyme attachment to $\alpha$ 1,4-linked glucose monomers [27], while CBM6 domains have been shown to target the parent enzyme to cellulose, xylooligosaccharides, and mixed linkage glucans $[28,29]$. The possible functional association of these four proteins with the membrane and cell wall remains to be assessed. Homology to the functionally characterized Bacillus subtilis subsp. subtilis ATCC $6051 \mathrm{XynD}$ [30] suggests that Xsa43A may target intact or partially degraded arabinose containing xylans, hydrolysing $(1 \rightarrow 2)-\alpha-$ linked and $(1 \rightarrow 3)$ - $\alpha$-linked L-arabinofuranosyl groups from xylooligosaccharides of varying lengths. It is possible that Xsa43A augments the activity of the secreted Xsa43J [10] to hydrolyse $\alpha$-linked L-arabinofuranosyl groups from the xylan backbone. GH13 pullulanases (EC 3.2.1.41) (also called debranching enzymes) hydrolyze $\alpha-1,6$ glycosidic linkages in polymers such as starch, pullulan, and other branched oligosaccharides, generating $\alpha-1,4$ linked linear oligosaccharides. Although the catalytic domain of GH30A is similar to the GH30 domain found within the Xsa43J [10], without functional analysis it is difficult to predict the catalytic potential of the GH30A enzyme. Functional analysis is also required to predict the catalytic activity of Bgl3 A.

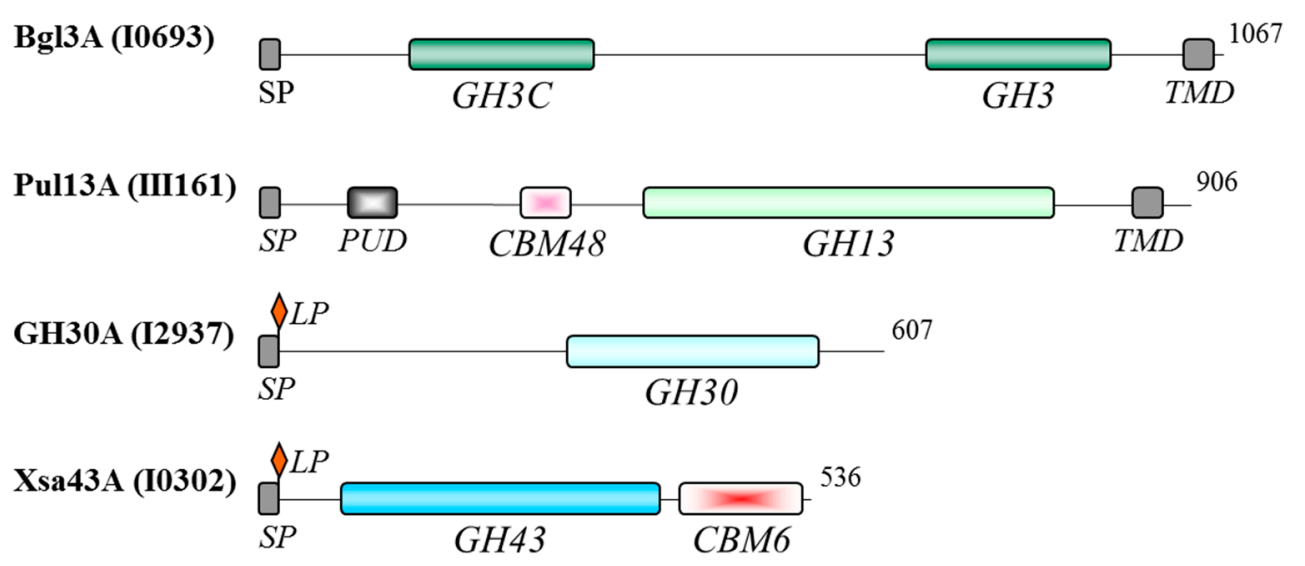

Figure 4. Functional domains of predicted secreted polysaccharidases identified in the $B$. proteoclasticus cytosol. Residue length is indicated to the right of each enzyme. CBM, carbohydrate-binding module; LP, lipobox motif; PUD, bacterial pullulanase-associated domain; SP, secretory signal peptide; TMD, transmembrane domain. 
The remaining 20 identified oligosaccharidases are predicted to be localized to the cytoplasm. This group of enzymes included three members each of the GH2 and GH3 families and single representatives of 11 other GH families (Figure 5). Two esterase families and a glycosyl transferase were also represented. Several enzymes contained more than one predicted catalytic domain, including all the GH3 family enzymes that contained GH3 and GH3C catalytic domains, and the $\beta$-galactosidase Bga2A that contained three catalytic domains. A distinguishing feature of both the GH43 xylosidase/arabinofuranosidase/esterase $\mathrm{Xsa} 43 \mathrm{H}$ and the GH10 endo-1,4- $\beta$-xylanase/esterase Xyn10D was that each of those proteins contained two putative catalytic domains that were predicted to be active upon different substrates, namely $\mathrm{GH}$ and $\mathrm{CE}$ activities. Interestingly, among the predicted cytosolic enzymes a CBMX domain was found within the N-terminal region of the GH94 cellobiose phosphorylase, and a CelD domain is predicted in the GH9 cellodextrinase. Both non-catalytic domains are often associated with these types of enzymes, and both may play a role in enzyme/substrate attachment.
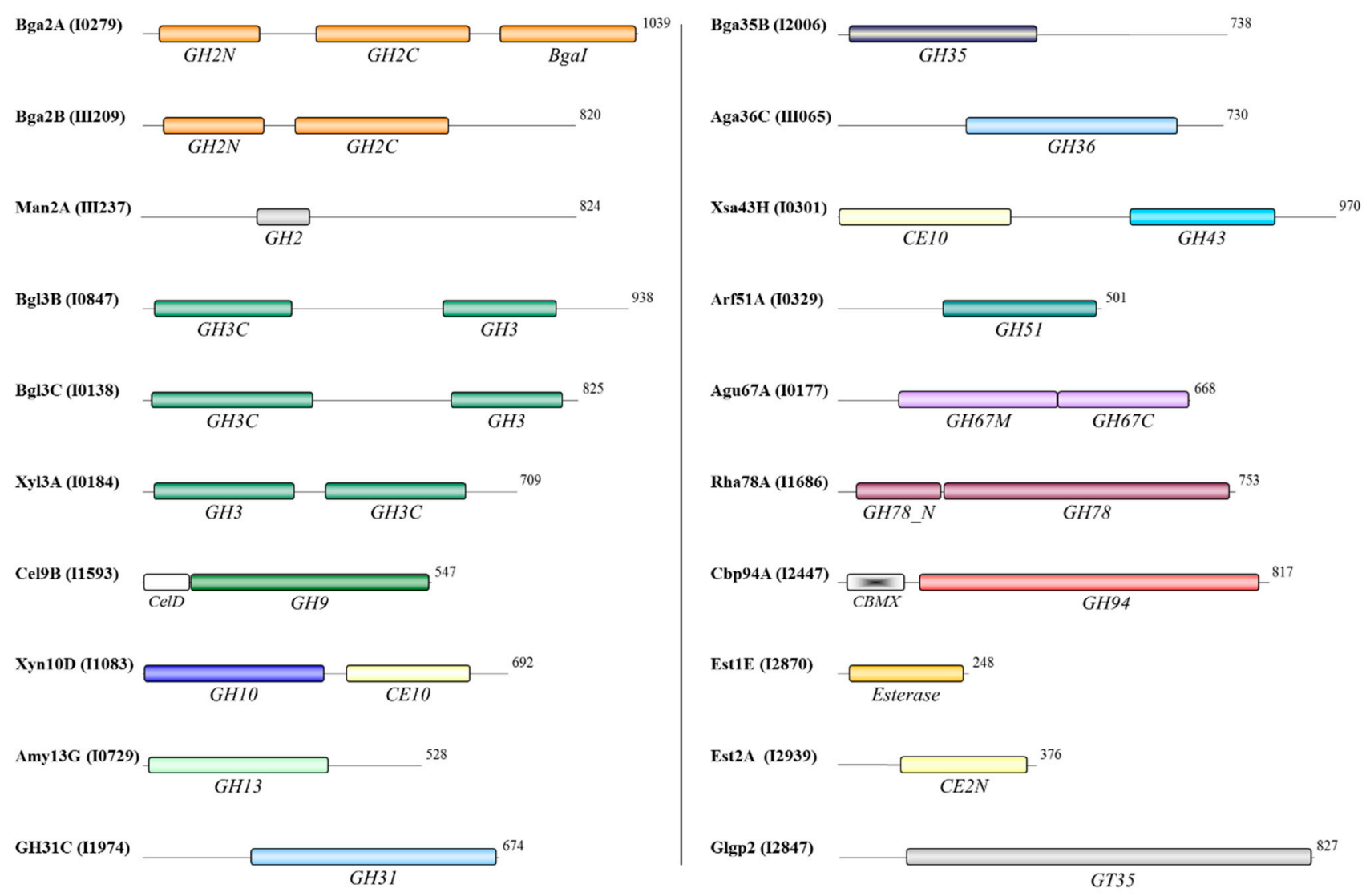

Figure 5. Functional domains of predicted cytoplasmic oligosaccharidases identified in the B. proteoclasticus cytosol.

\subsection{Effects of Growth on Xylan or Xylose}

To further investigate the potential roles of carbohydrate metabolizing enzymes in the processing of xylan, 2DE was used to quantify the effects of growth substrate and growth phase on the relative abundance of fibrolytic enzymes and transport proteins. Table 3 and Supplementary Figure S1 summarize mid-log phase proteins that differed in abundance between cells grown on xylose or xylan. 
Three biological replicates (separate cultures) were analyzed for each substrate and growth condition, and each biological replicate was analyzed on triplicate gels. Four of the identified enzymes were only detected in cells grown on xylan. Two ABC transporter substrate-binding proteins were unique to growth on xylan. Pullulanase (Pul13A) was detected as a pair of adjacent spots at approximately $\mathrm{p} I 4.2$ and $100 \mathrm{kDa}$, which corresponded closely with the theoretical values for this protein. The more acidic form was also only detected in cells grown on xylan, while the more basic form was 2.8 times more abundant in cells grown on xylan compared to xylose. A further eight protein spots showed greater than two-fold differences $(p<0.05)$ between growth on xylan compared to xylose, although two of these spots, C733 and C1010, each contained two identified proteins. The most strongly up- and down-regulated proteins in the mid-log phase proteome of xylan grown cells were a subtilisin family serine protease and glutamate synthase GltA, respectively.

Table 3. Summary of the differentially abundant proteins between xylan and xylose identified in the mid-log phase cytosolic proteome.

\begin{tabular}{|c|c|c|c|c|c|c|c|c|}
\hline Spot & Protein & Locus & Function ${ }^{\mathrm{i}}$ & Expect. ii & $\mathbf{p} I$ & kDa & Fold-Change iii & $p$ Value \\
\hline $\mathrm{C} 853$ & Adenylosuccinate lyase, PurB & Bpr_I2212 & $\mathrm{O}$ & $1.2 \times 10^{-10}$ & 5.4 & 53.7 & $-3.1 \pm 0.6$ & 0.001 \\
\hline $\mathrm{C} 1135$ & $\begin{array}{c}\text { Amino acid } \mathrm{ABC} \text { transporter substrate- } \\
\text { binding protein }\end{array}$ & Bpr_I1826 & $\mathrm{T}$ & $5.8 \times 10^{-4}$ & 4.0 & 31.6 & Xylan & $\mathrm{n} / \mathrm{a}$ \\
\hline \multirow[t]{2}{*}{$\mathrm{C} 1010$} & $\begin{array}{c}\text { Anti-sigma factor } \\
\text { antagonist/phosphotransferase } \\
\text { domain-containing protein }\end{array}$ & Bpr_I0249 & $\mathrm{R}$ & \multirow[t]{2}{*}{$3.0 \times 10^{-30}$} & 4.6 & 49.8 & \multirow[t]{2}{*}{$-12.0 \pm 0.7$} & \multirow[t]{2}{*}{0.001} \\
\hline & Ribosomal protein S1, RpsA & Bpr_I2035 & $\mathrm{Q}$ & & 4.6 & 41.9 & & \\
\hline C654 & $\begin{array}{l}\text { DNA-directed RNA polymerase } \alpha \\
\text { subunit, RpoA }\end{array}$ & Bpr_I0623 & $\mathrm{W}$ & $3.0 \times 10^{-17}$ & 4.4 & 35.1 & $-8.7 \pm 4.3$ & 0.002 \\
\hline $\mathrm{C} 837$ & $\begin{array}{c}\text { Fructose-1,6-bisphosphate } \\
\text { aldolase, FbaA }\end{array}$ & Bpr_I2903 & $\mathrm{C}$ & $3.0 \times 10^{-13}$ & 5.1 & 30.5 & $-2.1 \pm 0.2$ & 0.002 \\
\hline \multirow{2}{*}{$\mathrm{C} 733$} & IMP cyclohydrolase, PurO & Bpr_I0731 & $\mathrm{O}$ & \multirow{2}{*}{$1.5 \times 10^{-18}$} & 4.7 & 32.2 & \multirow{2}{*}{$2.3 \pm 0.5$} & \multirow{2}{*}{0.001} \\
\hline & Translation elongation factor Tu, TufA & Bpr_I2364 & Q & & 4.82 & 43.6 & & \\
\hline C792 & $\begin{array}{l}\text { NADPH-dependent glutamate synthase, } \\
\text { GltA3 }\end{array}$ & Bpr_I1306 & A & $1.9 \times 10^{-4}$ & 5.0 & 49.3 & $-15.8 \pm 6.3$ & 0.001 \\
\hline C637 & Pullulanase, Pul13A & Bpr_III161 & $\mathrm{C}$ & $1.5 \times 10^{-9}$ & 4.4 & 99.7 & $2.8 \pm 0.3$ & 0.001 \\
\hline C638 & Pullulanase, Pul13A & Bpr_III161 & $\mathrm{C}$ & $1.8 \times 10^{-6}$ & 4.4 & 99.7 & Xylan & $\mathrm{n} / \mathrm{a}$ \\
\hline $\mathrm{C} 709$ & Ribosomal protein S1, RpsA & Bpr_I2035 & $\mathrm{Q}$ & $9.6 \times 10^{-19}$ & 4.6 & 41.9 & $-4.1 \pm 1.1$ & 0.001 \\
\hline $\mathrm{C} 1072$ & Serine protease subtilisin family & Bpr_I2629 & $\mathrm{P}$ & $3.8 \times 10^{-8}$ & 3.8 & 153.3 & $5.8 \pm 1.3$ & 0.001 \\
\hline C1074 & $\begin{array}{l}\text { Sugar ABC transporter } \\
\text { substrate-binding protein }\end{array}$ & Bpr_I0182 & $\mathrm{T}$ & $1.5 \times 10^{-8}$ & 4.12 & 63.3 & Xylan & $\mathrm{n} / \mathrm{a}$ \\
\hline
\end{tabular}

i A, Amino acid biosynthesis; C, Carbohydrate metabolism; O, Nucleotide metabolism; P, Protein fate; Q, Protein synthesis; R, Regulation; T, Transporters; W, Transcription; ${ }^{i i}$ Expectation value is the statistical probability of the top ranked protein match being a false positive identification, $p<0.05$; iii Fold-change was calculated as the ratio of the mean normalized protein spot volumes in the xylan versus xylose growth conditions as stated. Positive values denote proteins with increased mean normalized spot volume in xylan grown cells. "Xylan" denotes the protein was uniquely detected in culture medium harvested from xylan grown cells. In these cases it was not possible to calculate a $p$ Value and "n/a" (non-applicable) is entered. 
For cells harvested at stationary growth phase, two identified proteins were detected only in cells grown on xylan. They were a sugar ABC transporter substrate-binding protein (abundant spot C1074) and an amino acid ABC transporter substrate-binding protein (minor spot C1135) (Table 4, Supplementary Figure S2) that were also unique to growth on xylan in mid-log phase cells. The high abundance of the sugar transport protein Bpr_I0182 is in good agreement with its increased abundance in the membrane fraction of B. proteoclasticus grown with xylan compare to fructose [13]. In addition, the more basic pullulanase identified in mid-log phase xylan-grown cells was replaced by a spot of slightly lower mass that was also identified as this protein. Other identified proteins differed quantitatively between cells grown on xylan compared to xylose. Analysis of the differences was complicated by identification of two proteins in each of the spots C704, C785, and C1120. C1120 contained $\beta$-galactosidase Bga35A and $\beta$-xylosidase Xyl3A and was more abundant after growth in xylan. In contrast, the xylose $\mathrm{ABC}$ transporter substrate-binding protein product of Bpr_I1173 (spot C1057) was less abundant in xylan-grown cells. A U62 family peptidase identified in spot C784 (Bpr_I2456) was also more abundant in xylan grown cells. This peptidase was up to $51 \%$ identical to many clostridial zinc-dependent proteases and U62 family peptidases that modulate DNA gyrase activity [31].

Table 4. Summary of the differentially abundant proteins between xylan and xylose identified in the stationary phase cytosolic proteome.

\begin{tabular}{|c|c|c|c|c|c|c|c|c|}
\hline Spot & Protein & Locus & Function $^{\mathrm{i}}$ & Expect. ii & $\mathrm{p} I$ & kDa & Fold-Change iii & $p$ Value \\
\hline C1135 & $\begin{array}{c}\text { Amino acid } \mathrm{ABC} \text { transporter } \\
\text { substrate-binding protein }\end{array}$ & Bpr_I1826 & $\mathrm{T}$ & $5.8 \times 10^{-4}$ & 4.0 & 31.6 & Xylan & $\mathrm{n} / \mathrm{a}$ \\
\hline \multirow[t]{2}{*}{ C785 } & $\begin{array}{c}\text { Aminotransferase } \\
\text { DegT/DnrJ/EryC1/StrS family }\end{array}$ & Bpr_I2311 & I & \multirow[t]{2}{*}{$1.5 \times 10^{-10}$} & 5.0 & 51.0 & \multirow[t]{2}{*}{$4.2 \pm 1.1$} & \multirow[t]{2}{*}{0.001} \\
\hline & Xylulokinase, XylB & Bpr_I0173 & $\mathrm{C}$ & & 4.9 & 53.7 & & \\
\hline \multirow{2}{*}{ C1120 } & $\beta$-Galactosidase, Bga35B & Bpr_I2006 & $\mathrm{C}$ & \multirow{2}{*}{$1.9 \times 10^{-27}$} & 4.9 & 83.2 & \multirow{2}{*}{$4.5 \pm 0.8$} & \multirow{2}{*}{0.001} \\
\hline & $\beta$-Xylosidase, Xyl3A & Bpr_I0184 & $\mathrm{C}$ & & 4.8 & 78.2 & & \\
\hline \multirow[b]{2}{*}{ C704 } & Hypothetical protein & Bpr_I2455 & $\mathrm{H}$ & \multirow[b]{2}{*}{$7.6 \times 10^{-22}$} & 4.7 & 47.7 & \multirow[b]{2}{*}{$2.3 \pm 0.1$} & \multirow[b]{2}{*}{0.001} \\
\hline & $\begin{array}{c}\text { Phosphoribosylamine-glycine } \\
\text { ligase, PurD }\end{array}$ & Bpr_I0870 & $\mathrm{O}$ & & 4.7 & 46.3 & & \\
\hline C601 & $\begin{array}{c}\text { Oligopeptide } \mathrm{ABC} \\
\text { transporter substrate-binding } \\
\text { protein, OppA1 }\end{array}$ & Bpr_I1276 & $\mathrm{T}$ & $1.9 \times 10^{-13}$ & 4.0 & 83.1 & $2.3 \pm 0.5$ & 0.001 \\
\hline $\mathrm{C} 784$ & Peptidase U62 family & Bpr_I2456 & $\mathrm{P}$ & $6.1 \times 10^{-9}$ & 4.8 & 52.3 & $14.7 \pm 4.6$ & 0.001 \\
\hline $\mathrm{C} 1074$ & $\begin{array}{l}\text { Sugar ABC transporter substrate- } \\
\text { binding protein }\end{array}$ & Bpr_I0182 & $\mathrm{T}$ & $7.6 \times 10^{-7}$ & 4.12 & 63.3 & Xylan & $\mathrm{n} / \mathrm{a}$ \\
\hline $\mathrm{C} 1057$ & $\begin{array}{l}\text { Xylose ABC transporter substrate- } \\
\text { binding protein }\end{array}$ & Bpr_I1173 & $\mathrm{T}$ & $9.6 \times 10^{-12}$ & 4.2 & 38.4 & $-3.9 \pm 1.1$ & 0.001 \\
\hline
\end{tabular}

${ }^{\mathrm{i}}$ C, Carbohydrate metabolism; H, Hypothetical; I, Cell envelope; O, Nucleotide metabolism; P, Protein fate; T, Transporters; ${ }^{\text {ii }}$ Expectation value is the statistical probability of the top ranked protein match being a false positive identification, $p<0.05$; ${ }^{\text {iii }}$ Fold-change was calculated as the ratio of the mean normalized protein spot volumes in the xylan versus xylose growth conditions as stated. Positive values denote proteins with increased mean normalized spot volume in xylan grown cells. "Xylan" denotes the protein was uniquely detected in culture medium harvested from xylan grown cells. In these cases it was not possible to calculate a $p$ Value and " $\mathrm{n} / \mathrm{a}$ " (non-applicable) is entered. 


\subsection{Predicted Activities and Pathways}

The results of this study are consistent with the model of $B$. proteoclasticus polysaccharide metabolism that has emerged from the genomic [9], and proteomic analyses of the extracellular [10] and membrane compartments [13]. This model proposes that a core set of secreted enzymes target primarily the xylan backbone and are therefore likely to liberate a range of substituted or unsubstituted xylooligosaccharides. One caution is that gene identifications were based on homology with other bacterial sequences, where possible experimental evidence for function is described below. The GH10 endoxylanase Xyn10B that was detected at high abundance in the growth medium of cells grown in the presence of xylan [10] is expected to produce xylooligomers with arabinofuranosyl, $O$-acetyl, glucuronyl, and ferulic acid substituents [32-35]. B. proteoclasticus also appears to synthesize several sugar binding protein dependent, $\mathrm{ABC}$-transporter systems that presumably allow it to actively transport these substituted xylooligomers across the cell membrane for further metabolism [10,13]. Such a model requires $B$. proteoclasticus to possess a range of cytosolic enzymes that are capable of processing substituted xylooligomers to their constituent monomers.

The oligosaccharidases identified in the B. proteoclasticus cytoplasm (Table 5) include enzymes with potential to hydrolyze ferulated glucuroarabinoxylans, acetyl and glucuronic acid substituted sugars, as well as xylobiose and arabinogalactans (Figure 6), all of which are the expected products of extracellular xylan degradation [10]. Other identified oligosaccharide degrading enzymes including a glycogen phosphorylase (consistent with the demonstration of glycogen-like storage polysaccharide in B316 $\left.{ }^{\mathrm{T}}[9]\right), \alpha$-amylase, pullulanase, and cellobiose phosphorylase that are implicated in the breakdown of storage polysaccharides.

Table 5. Predicted catalytic activities of the identified cytoplasmic oligosaccharide metabolizing enzymes.

\begin{tabular}{|c|c|c|c|}
\hline Protein & Locus & Substrate & Reaction Catalysed $^{\mathrm{i}}$ \\
\hline $\begin{array}{l}\beta \text {-Galactosidase, Bga2A } \\
\beta \text {-Galactosidase, Bga2B } \\
\beta \text {-Galactosidase, Bga35B }\end{array}$ & $\begin{array}{l}\text { Bpr_I0279 } \\
\text { Bpr_III209 } \\
\text { Bpr_I2006 }\end{array}$ & $\beta$-D-Galactosides & $\begin{array}{l}\text { Hydrolysis of terminal, non-reducing } \\
\beta \text {-D-galactose residues. }\end{array}$ \\
\hline$\beta$-Mannosidase, Man2A & Bpr_III237 & $\beta$-D-Mannosides & $\begin{array}{l}\text { Hydrolysis of terminal, non-reducing } \\
\beta \text {-D-mannose residues. }\end{array}$ \\
\hline $\begin{array}{l}\beta \text {-Glucosidase, } \mathrm{Bgl} 3 \mathrm{~B} \\
\beta \text {-Glucosidase, } \mathrm{Bgl} 13 \mathrm{C}\end{array}$ & $\begin{array}{l}\text { Bpr_I0847 } \\
\text { Bpr_I0138 }\end{array}$ & $\beta$-D-Glucosides & $\begin{array}{l}\text { Hydrolysis of terminal, non-reducing } \beta \text {-D-glucosyl } \\
\text { residues with release of } \beta \text {-D-glucose. }\end{array}$ \\
\hline$\beta$-Xylosidase, Xyl3A & Bpr_I0184 & $1,4-\beta$-D-Xylans & Hydrolysis of terminal, non-reducing D-xylose residues. \\
\hline Cellodextrinase, Cel9B & Bpr_I1593 & $\begin{array}{l}\text { Cellulose, lichenin and } \\
\text { cereal } \beta \text {-D-glucans }\end{array}$ & Endohydrolysis of $(1 \rightarrow 4)-\beta$-D-glucosidic linkages. \\
\hline $\begin{array}{l}\text { Endo-1,4- } \beta \text {-xylanase and } \\
\text { esterase, Xyn10D }\end{array}$ & Bpr_I1083 & $1,4-\beta$-D-Xylans & Endohydrolysis of $(1 \rightarrow 4)-\beta-D-x y l o s i d i c ~ l i n k a g e s$. \\
\hline$\alpha$-Amylase, Amy $13 \mathrm{G}$ & Bpr_I0729 & Starch and glycogen & Endohydrolysis of $(1 \rightarrow 6)$ - $\alpha$-D-glucosidic linkages. \\
\hline $\begin{array}{l}\text { Glycoside hydrolase family } 31 \text {, } \\
\text { GH31C }\end{array}$ & Bpr_I1974 & Unknown & Unknown. \\
\hline$\alpha$-Galactosidase, Aga36C & Bpr_III065 & $\alpha$-D-Galactosides & $\begin{array}{l}\text { Hydrolysis of terminal, non-reducing } \\
\alpha \text {-D-galactose residues. }\end{array}$ \\
\hline
\end{tabular}


Table 5. Cont.

\begin{tabular}{|c|c|c|c|}
\hline Protein & Locus & Substrate & Reaction Catalysed $^{\mathrm{i}}$ \\
\hline $\begin{array}{l}\text { Xylosidase/arabinofuranosidase } \\
\text { and esterase, } \mathrm{Xsa} 43 \mathrm{H}\end{array}$ & Bpr_I0301 & $\begin{array}{l}\alpha \text {-L-Arabinosides and } \\
\text { triacylglycerols }\end{array}$ & $\begin{array}{l}\text { Hydrolysis of terminal, non-reducing D-xylose or } \\
\alpha \text {-L-arabinofuranoside residues/hydrolysis of triacylglycerols } \\
\text { with release of a diacylglycerol } \\
\text { and a carboxylate. }\end{array}$ \\
\hline $\begin{array}{l}\alpha \text {-L-Arabinofuranosidase, } \\
\text { Arf51A }\end{array}$ & Bpr_I0329 & $\alpha$-L-Arabinofuranosides & $\begin{array}{l}\text { Hydrolysis of terminal, non-reducing } \\
\alpha \text {-L-arabinofuranoside residues. }\end{array}$ \\
\hline$\alpha$-D-Glucuronidase, Agu67A & Bpr_I0177 & Glucuronoxylans & $\begin{array}{l}\text { Hydrolysis of glucuronic acid substituted } \\
\text { xylooligosaccharides. }\end{array}$ \\
\hline$\alpha$-L-Rhamnosidase, Rha78A & Bpr_I1686 & $\alpha$-L-Rhamnosides & $\begin{array}{l}\text { Hydrolysis of terminal, non-reducing } \\
\alpha \text {-L-rhamnose residues. }\end{array}$ \\
\hline $\begin{array}{l}\text { Cellobiose phosphorylase, } \\
\text { Cbp94A }\end{array}$ & Bpr_I2447 & Cellobiose & Hydrolysis of cellobiose. \\
\hline Feruloyl esterase, Est1E & Bpr_I2870 & $\begin{array}{l}\text { Esterified } \\
\text { oligosaccharides }\end{array}$ & Deferuloylation of esterified oligosaccharides. \\
\hline Acetyl-xylan esterase, Est2A & Bpr_I2939 & $\begin{array}{l}\text { Acetylated xylans and } \\
\text { xylo-oligosaccharides }\end{array}$ & Deacetylation of xylans and xylo-oligosaccharides. \\
\hline Glycogen phosphorylase, Glgp2 & Bpr_I2847 & $1,4-\alpha$-D-Glucans & $\begin{array}{l}\text { Exohydrolysis and phosphorylation } \\
\text { of }(1 \rightarrow 4)-\alpha \text {-D-glucan. }\end{array}$ \\
\hline
\end{tabular}

${ }^{\mathrm{i}}$ Swiss Institute of Bioinformatics Enzyme nomenclature (http://us.expasy.org/enzyme/).

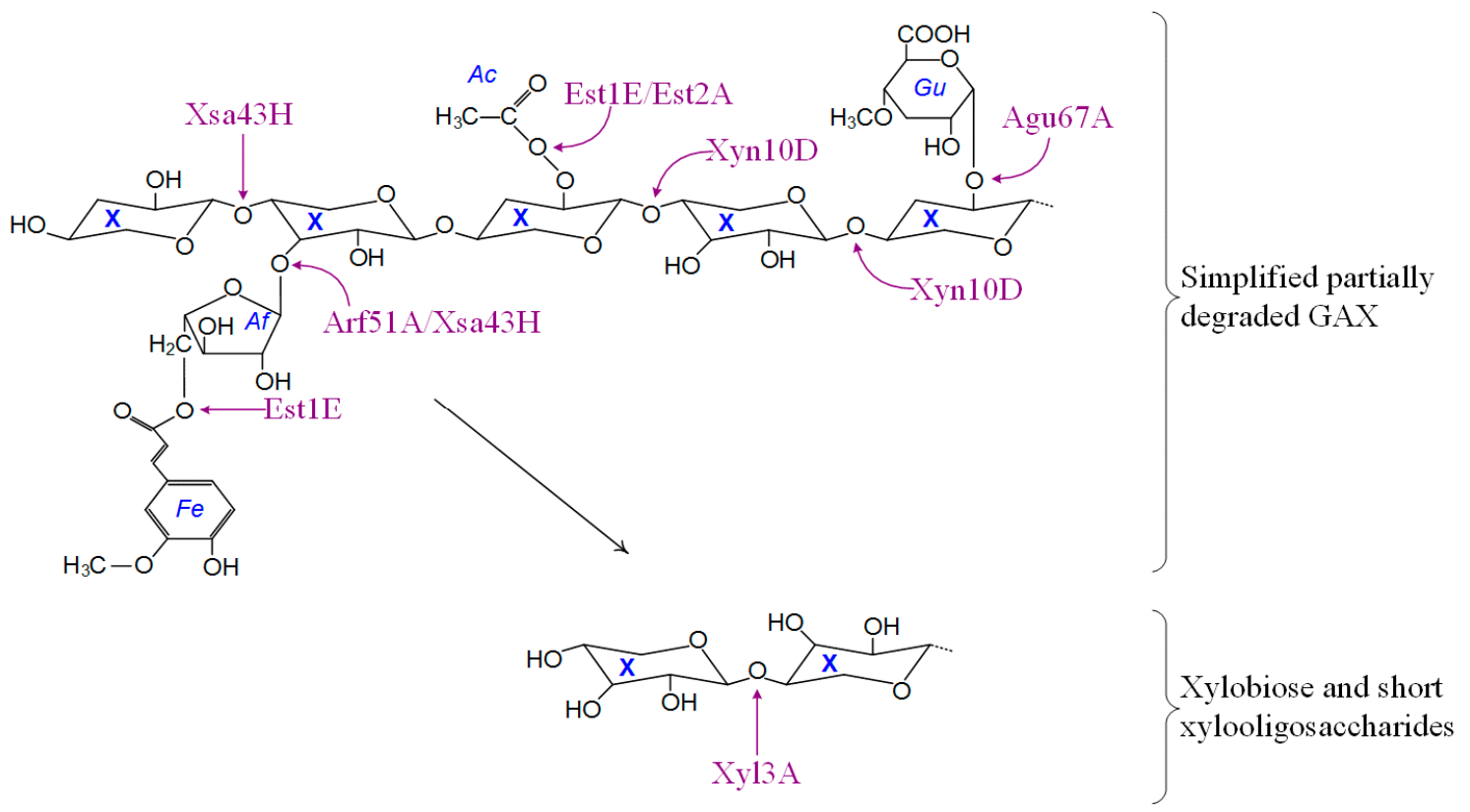

Figure 6. Schematic summary of the intracellular metabolism of oligosaccharides by $B$. proteoclasticus. Abbreviations: Ac, $O$-acetyl; Af, $\alpha$-L-arabinofuranose; Fe, ferulic acid; GAX, glucuronoarabinoxylan; Gu, 4-O-methyl-D-glucuronic acid; X, xylopyranose (xylose).

Based upon either direct functional characterization or homology to other bacterial enzymes with known catalytic activities, the diverse range of internalized substituted xylooligosaccharide are expected to be targeted by enzymes including two acetyl-xylan esterases (Est1E and Est2A), two 
enzymes with arabinofuranosidase catalytic potential (Arf51A and Xsa43H), at least one glucuronidase (Agu67A), and a multi-domain endoxylanase (Xyn10D). Both acetyl-xylan esterases have been functionally characterized [36,37]. Est1E is the only enzyme of its type identified in the B. proteoclasticus proteome and may be an important mediator of the degradation and assimilation of feruloyl xylooligosaccharides. When incubated with esterified synthetic substrates or purified rye-grass hemicellulose, Est1E released ferulic and p-coumaric acids [37]. In addition, a variety of ester linkages were hydrolyzed and phenolic compounds released when Est1E was incubated with birch-wood xylan, suggesting that the enzyme has wide substrate specificity. Est2A was confirmed as having true acetyl-xylan esterase activity [36], and may therefore target only acetylated xylooligosaccharides.

Homology to characterized enzymes from other bacterial species suggests that Arf51A, Agu67A, and $\mathrm{Xsa} 43 \mathrm{H}$ are likely to mediate almost complete hydrolysis of xylooligosaccharide substituent groups. Arf51A is homologous to several Clostridial $\alpha$-L-arabinofuranosidases [38-40] that preferentially hydrolyzed arabinose containing polysaccharides such as wheat arabinoxylan over other hemicellulosic substrates. Agu67A is structurally and functionally similar to several well-characterized bacterial GH67 enzymes [41-43] that are induced by, and are active upon, methylglucuronoxylan, which suggests that Agu67A is likely to remove 4-O-methylglucuronic acid residues from the backbone of assimilated methyglucuronoxylooligosaccharides. $\alpha$-D-Glucuronidases cleave the $\alpha$-1,2-glycosidic linkage between 4-O-methyl-D-glucuronic acid and the xylan backbone, and are vital for the complete degradation of hemicelluloses such as GAX. The C-terminal, GH43 domain of $\mathrm{Xsa} 43 \mathrm{H}$ was at $65 \%$ identical to $C$. stercorarium xylosidase/arabinofuranosidase (XylA), which was particularly interesting in that at an optimal $\mathrm{pH}$ of 7.0 it exhibited xylosidase and arabinofuranosidase activity within the single GH43 domain [44].

Xyn10D was the only endoxylanase identified in the B. proteoclasticus cytosol and contains an N-terminal GH10 catalytic domain, as well a C-terminal CE10 domain, and the full-length protein is 97\% identical to the $B$. fibrisolvens $\mathrm{H} 17 \mathrm{c}(\mathrm{SA}) \mathrm{XynB}$, now designated as a strain of $B$. proteoclasticus $[4,45]$. When expressed in E. coli, XynB was able to cleave the backbone of xylooligomers close to sites of arabinose substitution, which are known to negatively influence the activity of many endoxylanases upon the xylan backbone [11]. A feature of Xyn10D is that similar to Xsa43H, it contains a novel N-terminal CE10 domain implying that both enzymes might possess novel catalytic activity within the rumen microbiome.

Following the removal of xylooligomer substituents, the $\beta$-xylosidase Xyl3A that contains two non-homologous GH3 functional domains (Figure 5) is expected to complete the hydrolysis of xylobiose and xylooligosaccharides to xylose monomers that can then enter the central metabolic pathways. Xyl3A is $53 \%$ identical and $71 \%$ similar to Bxl3B from Clostridium stercorarium NCIMB 11754, which hydrolyzes xylose from the non-reducing end of xylotriose, liberates only small amounts of xylose from synthetic- $\alpha$-arabinofuranoside, and does not release xylose from intact arabinoxylan or arabinose substituted xylooligosaccharides. Xyl3A was the only enzyme of its type identified in the B. proteoclasticus cytosol. Taken together these data suggest that the B. proteoclasticus Xyl3A may act exclusively on the non-reducing ends of short chain xylooligosaccharides and is a vital component of the cytosolic xylooligosaccharide degrading capability of B. proteoclasticus. 


\section{Conclusions}

Proteomic examination of the $B$. proteoclasticus cytosolic proteome has provided further insight into the xylan degrading enzyme system that has evolved to enable $B$. proteoclasticus to degrade and utilize xylan $[3,4]$, and provides a clearer understanding of the metabolic processes involved in plant cell-wall degradation by the fibrolytic rumen microbiota. Efficient xylan utilization requires the synergistic action of a variety of enzymes, including acetyl-xylan- and ferulic acid esterases, $\alpha$-L-arabinofuranosidases, $\alpha$-D-glucuronidases, endo-xylanases and $\beta$-xylosidases. This study confirms that $B$. proteoclasticus possesses the enzymes required for the cytosolic degradation of internalized substituted oligosaccharides that are predicted to be derived from extracellular xylan degradation $[9,10,13,36,37]$, and supports the notion that $B$. proteoclasticus makes an important contribution to ruminant metabolism.

This study also extends our understanding of the enzymes that are likely to play important roles in xylan degradation in the rumen. The use of exogenous fibrolytic enzymes as feed additives is an emerging technology that holds promise as a means of enhancing forage utilization and improving ruminant productivity [46-48]. Application of fibrolytic enzymes to rumen forage prior to consumption has resulted in increased voluntary intake, milk production, and average daily weight gain as a consequence of increased forage digestibility [49-55]. Nonetheless, results are inconsistent and not always positive [56-59]. Commercially prepared fibrolytic enzymes for ruminant applications are cocktails of crude enzyme extracts that usually contain specified levels of xylanase or cellulase activities and are assessed primarily on their capacity to degrade plant cell walls in vitro [47,60], rather than their specific formulations or the suitability of these formulations for their intended purposes. In particular, it has been suggested that side-chain hydrolyzing enzymes, such as ferulic acid esterases, acetyl-xylan esterases and arabinofuranosidases, should be incorporated [47]. This study has provided a clearer understanding of the specific enzymes that are utilized by a prominent hemicellulose degrading rumen microbe, and may assist in achieving the more rational and targeted design of multi-enzyme products aimed at enhancing the cell wall degradation of rumen forages.

\section{Acknowledgments}

This work was funded by grant C10X0314 from the New Economy Research Fund, administered by the New Zealand Foundation for Research, Science and Technology. We are grateful to Danyl McLauchlan for proteomics bioinformatics support

\section{Author Contributions}

GTA, WJK, JCD, JJB and TWJ conceived and planned the study. DL grew the cultures and harvested and fractionated the bacteria. JCD carried out the proteomics. LP led the LC-MS/MS. SCL and WJK carried out the bioinformatic analysis of gene functions. JCD wrote the manuscript with input from WJK, GTA and TWJ. 


\section{Conflicts of Interest}

The authors declare no conflict of interest.

\section{References}

1. Kulkarni, N.; Shendye, A.; Rao, M. Molecular and biotechnological aspects of xylanases. FEMS Microbiol. Rev. 1999, 23, 411-456.

2. Lombard, V.; Golaconda Ramulu, H.; Drula, E.; Coutinho, P.M.; Henrissat, B. The Carbohydrate-active enzymes database (CAZy) in 2013. Nucleic Acids Res. 2014, 42, D490-D495.

3. Attwood, G.T.; Reilly, K.; Patel, B.K.C. Clostridium proteoclasticum sp nov, a novel proteolytic bacterium from the bovine rumen. Int. J. Syst. Bacteriol. 1996, 46, 753-758.

4. Moon, C.D.; Pacheco, D.M.; Kelly, W.J.; Leahy, S.C.; Li, D.; Kopecny, J.; Attwood, G.T. Reclassification of Clostridium proteoclasticum as Butyrivibrio proteoclasticus comb. nov., a butyrate producing ruminal bacterium. Int. J. Syst. Evol. Microbiol. 2008, 58, 2041-2045.

5. Attwood, G.T.; Reilly, K. Identification of proteolytic rumen bacteria isolated from New Zealand cattle. J. Appl. Bacteriol. 1995, 79, 22-29.

6. Paillard, D.; McKain, N.; Rincon, M.T.; Shingfield, K.J.; Givens, D.I.; Wallace, R.J. Quantification of ruminal Clostridium proteoclasticum by real-time PCR using a molecular beacon approach. J. Appl. Microbiol. 2007, 103, 1251-1261.

7. Reilly, K.; Attwood, G.T. Detection of Clostridium proteoclasticum and closely related strains in the rumen by competitive PCR. Appl. Environ. Microbiol. 1998, 64, 907-913.

8. Edwards, J.E.; McEwan, N.R.; Travis, A.J.; Wallace, R.J. 16S rDNA library-based analysis of ruminal bacterial diversity. Antonie Van Leeuwenhoek Int. J. Gen. Mol. Microbiol. 2004, 86, 263-281.

9. Kelly, W.J.; Leahy, S.; Altermann, E.; Yeoman, C.J.; Dunne, J.C.; Kong, Z.; Pacheco, D.M.; Li, D.; Noel, S.; Moon, C.D.; et al. The glycobiome of the rumen bacterium Butyrivibrio proteoclasticus $\mathrm{B} 316^{\mathrm{T}}$ highlights adaptation to a polysaccharide-rich environment. PLoS ONE 2010, 8, e11942.

10. Dunne, J.C.; Li, D.; Kelly, W.J.; Leahy, S.C.; Bond, J.J.; Attwood, G.T.; Jordan, T.W. Extracellular polysaccharide-degrading proteome of Butyrivibrio proteoclasticus. J. Proteome Res. 2012, 11, 131-142.

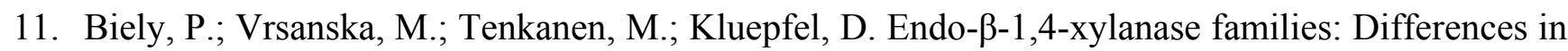
catalytic properties. J. Bacteriol. 1997, 57, 151-166.

12. Taguchi, H.; Koike, S.; Kobayashi, Y.; Cann, I.K.O.; Karita, S. Partial characterization of structure and function of a xylanase gene from the rumen hemicellulolytic bacterium Eubacterium ruminantium. Anim. Sci. J. 2004, 75, 325-332.

13. Bond, J.J.; Dunne, J.C.; Kwan, F.Y.S.; Li, D.; Zhang, K.K.; Leahy, S.C.; Kelly, W.J.; Attwood, G.T.; Jordan, T.W. Carbohydrate transporting membrane proteins of the rumen bacterium, Butyrivibrio proteoclasticus. J. Proteomics 2012, 75, 3138-3144. 
14. Carpentier, S.C.; Witters, E.; Laukens, K.; Deckers, P.; Swennen, R.; Panis, B. Preparation of protein extracts from recalcitrant plant tissues: An evaluation of different methods for two-dimensional gel electrophoresis analysis. Proteomics 2005, 5, 2497-2507.

15. Rawson, P.; Stockum, C.; Peng, L.; Manivannan, B.; Lehnert, K.; Ward, H.E.; Berry, S.D.; Davis, S.R.; Snell, R.G.; McLauchlan, D.; et al. Metabolic proteomics of the liver and mammary gland during lactation. J. Proteomics 2012, 75, 4429-4435.

16. Smit, A.M.; Strabala, T.J.; Peng, L.; Rawson, P.; Lloyd-Jones, G.; Jordan, T.W. Proteomic phenotyping of Novosphingobium nitrogenifigens reveals a robust capacity for simultaneous nitrogen fixation, polyhydroxyalkanoate production, and resistance to reactive oxygen species. Appl. Environ. Microbiol. 2012, 78, 4802-4815.

17. MASCOT. Available online: http://www.matrixscience.com/ (accessed on 23 Ocotber 2015).

18. Altschul, S.F.; Gish, W.; Miller, W.; Myers, E.W.; Lipman, D.J. Basic Local Alignment Search Tool. J. Mol. Biol. 1990, 215, 403-410.

19. Finn, R.D.; Tate, J.; Mistry, J.; Coggill, P.C.; Sammut, S.J.; Hotz, H.R.; Ceric, G.; Forslund, K.; Eddy, S.R.; Sonnhammer, E.L.L.; et al. The Pfam protein families database. Nucleic Acids Res. 2008, 36, D281-D288.

20. Haft, D.H.; Selengut, J.D.; White, O. The TIGRFAMs database of protein families. Nucleic Acids Res. 2003, 31, 371-373.

21. Larkin, M.A.; Blackshields, G.; Brown, N.P.; Chenna, R.; McGettigan, P.A.; McWilliam, H.; Valentin, F.; Wallace, I.M.; Wilm, A.; Lopez, R.; et al. Clustal W and Clustal X version 2.0. Bioinformatics 2007, 23, 2947-2948.

22. Bendtsen, J.D.; Nielsen, H.; von Heijne, G.; Brunak, S. Improved prediction of signal peptides: SignalP 3.0. J. Mol. Biol. 2004, 340, 783-795.

23. Juncker, A.S.; Willenbrock, H.; von Heijne, G.; Brunak, S.; Nielsen, H.; Krogh, A. Prediction of lipoprotein signal peptides in Gram-negative bacteria. Protein Sci. 2003, 12, 1652-1662.

24. Sutcliffe, I.C.; Harrington, D.J. Pattern searches for the identification of putative lipoprotein genes in Gram-positive bacterial genomes. Microbiology-SGM 2002, 148, 2065-2077.

25. Krogh, A.; Larsson, B.; von Heijne, G.; Sonnhammer, E.L.L. Predicting transmembrane protein topology with a hidden Markov model: Application to complete genomes. J. Mol. Biol. 2001, 305, 567-580.

26. Hirokawa, T.; Boon-Chieng, S.; Mitaku, S. SOSUI: Classification and secondary structure prediction system for membrane proteins. Bioinformatics 1998, 14, 378-379.

27. Machovic, M.; Janecek, S. Domain evolution in the GH13 pullulanase subfamily with focus on the carbohydrate-binding module family 48. Biologia 2008, 63, 1057-1068.

28. Correia, M.A.S.; Pires, V.M.R.; Gilbert, H.J.; Bolam, D.N.; Fernandes, V.O.; Alves, V.D.; Prates, J.A.M.; Ferreira, L.M.A.; Fontes, C. Family 6 carbohydrate-binding modules display multiple $\beta$-1,3-linked glucan-specific binding interfaces. FEMS Microbiol. Lett. 2009, 300, $48-57$.

29. Henshaw, J.L.; Bolam, D.N.; Pires, V.M.R.; Czjzek, M.; Henrissat, B.; Ferreira, L.M.A.; Fontes, C.; Gilbert, H.J. The Family 6 carbohydrate binding module CmCBM6-2 contains two ligand-binding sites with distinct specificities. J. Biol. Chem. 2004, 279, 21552-21559. 
30. Bourgois, T.M.; van Craeyveld, V.; van Campenhout, S.; Courtin, C.M.; Delcour, J.A.; Robben, J.; Volckaert, G. Recombinant expression and characterization of XynD from Bacillus subtilis subsp. subtilis ATCC 6051: A GH 43 arabinoxylan arabinofuranohydrolase. Appl. Microbiol. Biotechnol. 2007, 75, 1309-1317.

31. Nolling, J.; Breton, G.; Omelchenko, M.V.; Makarova, K.S.; Zeng, Q.D.; Gibson, R.; Lee, H.M.; Dubois, J.; Qiu, D.Y.; Hitti, J.; et al. Genome sequence and comparative analysis of the solvent-producing bacterium Clostridium acetobutylicum. J. Bacteriol. 2001, 183, 4823-4838.

32. Borneman, W.S.; Hartley, R.D.; Himmelsbach, D.S.; Ljungdahl, L.G. Assay for trans-para-coumaroyl esterase using a specific substrate from plant-cell walls. Anal. Biochem. 1990, 190, 129-133.

33. Hartley, R.D.; Morrison, W.H.; Himmelsbach, D.S.; Borneman, W.S. Cross-linking of cell-wall phenolic arabinoxylans in gramineous plants. Phytochemistry 1990, 29, 3705-3709.

34. Mueller-Harvey, I.; Hartley, R.D.; Harris, P.J.; Curzon, E.H. Linkage of para-coumaroyl and feruloyl groups to cell-wall polysaccharides of barley straw. Carbohydr. Res. 1986, 148, 71-85.

35. Vietor, R.J.; Angelino, S.; Voragen, A.G.J. Structural features of arabinoxylans from barley and malt cell-wall material. J. Cereal Sci. 1992, 15, 213-222.

36. Till, M.; Goldstone, D.C.; Attwood, G.T.; Moon, C.D.; Kelly, W.J.; Arcus, V.L. Structure and function of an acetyl xylan esterase (Est2A) from the rumen bacterium Butyrivibrio proteoclasticus. Proteins-Struct. Funct. Bioinform. 2013, 81, 911-917.

37. Goldstone, D.C.; Villas-Boas, S.G.; Till, M.; Kelly, W.J.; Attwood, G.T.; Arcus, V.L. Structural and functional characterization of a promiscuous feruloyl esterase (Est1E) from the rumen bacterium Butyrivibrio proteoclasticus. Proteins 2010, 78, 1457-1469.

38. Schwarz, W.H.; Bronnenmeier, K.; Krause, B.; Lottspeich, F.; Staudenbauer, W.L. Debranching of arabinoxylan - properties of the thermoactive recombinant $\alpha$-L-arabinofuranosidase from Clostridium-stercorarium (Arfb). Appl. Microbiol. Biotechnol. 1995, 43, 856-860.

39. Zverlov, V.V.; Liebl, W.; Bachleitner, M.; Schwarz, W.H. Nucleotide sequence of arfB of Clostridium stercorarium, and prediction of catalytic residues of $\alpha$-L-arabinofuranosidases based on local similarity with several families of glycosyl hydrolases. FEMS Microbiol. Lett. 1998, 164, 337-343.

40. Kosugi, A.; Murashima, K.; Doi, R.H. Characterization of two noncellulosomal subunits, ArfA and BgaA, from Clostridium cellulovorans that cooperate with the cellulosome in plant cell wall degradation. J. Bacteriol. 2002, 184, 6859-6865.

41. Golan, G.; Shallom, D.; Teplitsky, A.; Zaide, G.; Shulami, S.; Baasov, T.; Stojanoff, V.; Thompson, A.; Shoham, Y.; Shoham, G. Crystal structures of Geobacillus stearothermophilus $\alpha$-glucuronidase complexed with its substrate and products-Mechanistic implications. J. Biol. Chem. 2004, 279, 3014-3024.

42. Chow, V.; Nong, G.; Preston, J.F. Structure, Function, and Regulation of the Aldouronate Utilization Gene Cluster from Paenibacillus sp. Strain JDR-2. J. Bacteriol. 2007, 189, 8863-8870.

43. Shallom, D.; Golan, G.; Shoham, G.; Shoham, Y. Effect of dimer dissociation on activity and thermostability of the $\alpha$-glucuronidase from Geobacillus stearothermophilus: Dissecting the different oligomeric forms of Family 67 glycoside hydrolases. J. Bacteriol. 2004, 186, 6928-6937. 
44. Sakka, K.; Yoshikawa, K.; Kojima, Y.; Karita, S.; Ohmiya, K.; Shimada, K. Nucleotide-sequence of the Clostridium stercorarium xylA gene encoding a bifunctional protein with $\beta$-D-xylosidase and $\alpha$-L-arabinofuranosidase activities, and properties of the translated product. Biosci. Biotechnol. Biochem. 1993, 57, 268-272.

45. Lin, L.L.; Thomson, J.A. Cloning, sequencing and expression of a gene encoding a $73 \mathrm{kDa}$ xylanase enzyme from the rumen anaerobe Butyrivibrio fibrisolvens H17c. Mol. Gen. Genet. 1991, 228, 55-61.

46. Beauchemin, K.A.; Colombato, D.; Morgavi, D.P.; Yang, W.Z. Use of exogenous fibrolytic enzymes to improve feed utilization by ruminants. J. Anim. Sci. 2003, 81, E37-E47.

47. Yang, H.J.; Xie, C.Y. Assessment of fibrolytic activities of 18 commercial enzyme products and their abilities to degrade the cell wall fraction of corn stalks in in vitro enzymatic and ruminal batch cultures. Anim. Feed Sci. Technol. 2010, 159, 110-121.

48. Phakachoed, N.; Suksombat, W.; Colombatto, D.; Beauchemin, K.A. Use of fibrolytic enzymes additives to enhance in vitro ruminal fermentation of corn silage. Livest. Sci. 2013, 157, 100-112.

49. Schingoethe, D.J.; Stegeman, G.A.; Treacher, R.J. Response of lactating dairy cows to a cellulase and xylanase enzyme mixture applied to forages at the time of feeding. J. Dairy Sci. 1999, 82, 996-1003.

50. Kung, L.; Treacher, R.J.; Nauman, G.A.; Smagala, A.M.; Endres, K.M.; Cohen, M.A. The effect of treating forages with fibrolytic enzymes on its nutritive value and lactation performance of dairy cows. J. Dairy Sci. 2000, 83, 115-122.

51. Yang, W.Z.; Beauchemin, K.A.; Rode, L.M. A comparison of methods of adding fibrolytic enzymes to lactating cow diets. J. Dairy Sci. 2000, 83, 2512-2520.

52. Cruywagen, C.W.; van Zyl, W.H. Effects of a fungal enzyme cocktail treatment of high and low forage diets on lamb growth. Anim. Feed Sci. Technol. 2008, 145, 151-158.

53. Beauchemin, K.A.; Rode, L.M.; Sewalt, V.J.H. Fibrolytic enzymes increase fiber digestibility and growth rate of steers fed dry forages. Can. J. Anim. Sci. 1995, 75, 641-644.

54. Titi, H.; Lubbadeh, W.F. Effect of feeding cellulase enzyme on productive responses of pregnant and lactating ewes and goats. Small Rumin. Res. 2004, 52, 137-143.

55. Pinos-Rodriguez, J.M.; Gonzalez, S.S.; Mendoza, G.D.; Barcena, R.; Cobos, M.A.; Hernandez, A.; Ortega, M.E. Effect of exogenous fibrolytic enzyme on ruminal fermentation and digestibility of alfalfa and rye-grass hay fed to lambs. J. Anim. Sci. 2002, 80, 3016-3020.

56. ZoBell, D.R.; Wiedmeier, R.D.; Olson, K.C.; Treacher, R. The effect of an exogenous enzyme treatment on production and carcass characteristics of growing and finishing steers. Anim. Feed Sci. Technol. 2000, 87, 279-285.

57. Peters, A.; Lebzien, P.; Meyer, U.; Borchert, U.; Bulang, M.; Flachowsky, G. Effect of exogenous fibrolytic enzymes on ruminal fermentation and nutrient digestion in dairy cows. Arch. Anim. Nutr. 2010, 64, 221-237.

58. Aboagye, I.A.; Lynch, J.P.; Church, J.S.; Baah, J.; Beauchemin, K.A. Digestibility and growth performance of sheep fed alfalfa hay treated with fibrolytic enzymes and a ferulic acid esterase producing bacterial additive. Anim. Feed Sci. Technol. 2015, 203, 53-66. 
59. Torres, N.; Mendoza, G.D.; Barcena, R.; Loera, O.; Gonzalez, S.; Aranda, E.; Hernandez, P.A.; Crosby, M. Effects of various fibrolytic enzyme extracts on digestibility and productive performance of lambs fed a forage-based diet. Anim. Nutr. Feed Technol. 2013, 13, 381-389.

60. Colombatto, D.; Morgavi, D.P.; Furtado, A.F.; Beauchemin, K.A. Screening of exogenous enzymes for ruminant diets: Relationship between biochemical characteristics and in vitro ruminal degradation. J. Anim. Sci. 2003, 81, 2628-2638.

(C) 2015 by the authors; licensee MDPI, Basel, Switzerland. This article is an open access article distributed under the terms and conditions of the Creative Commons Attribution license (http://creativecommons.org/licenses/by/4.0/). 